\title{
Fully DSP-Based Control of an Active Voltage Conditioner
}

\author{
Vu Thi Ngoc Van, Nguyen Dinh Ngoc, Nguyen Huy Phuong, Vu Hoang Phuong*, \\ Nguyen Quang Dich, Tran Trong Minh \\ Hanoi University of Science and Technology, Hanoi, Vietnam \\ Email: phuong.vuhoang@hust.edu.vn
}

\begin{abstract}
One of the main problems in low voltage (LV) networks is related to sensitive load voltage stabilization close to the nominal value. This paper presents the analysis, design, and implementation of a back-to-back converter based active voltage conditioner for low voltage ( $L V)$ distribution grids to compensate short-term voltage sags or swells. The proposed voltage regulator contains an indirect AC/DC/AC converter and uses linear control associated with the pulse width modulation technique. To verify the practical usefulness of the proposed novel concept, a 5kVA three-phase prototype active voltage conditioner has been constructed, and the control system has been implemented based on 32-bit floating-point digital signal processor (DSP) TMS320F28377s. The effectiveness of the proposed method is demonstrated through the comprehensive experimental results.
\end{abstract}

Keywords: Active voltage conditioner, digital signal processor (DSP), voltage stabilization

\section{Introduction}

The voltage oscillations such as concavity due to earth fault of 1 phase have the proportion of $68 \%$ and $19 \%, 13 \%$ is corresponding with 2-phase, 3 -phase in a short period of time (a few grid periods up to tens of seconds). These oscillations will cause damage and interrupt some electrical and electronic equipment. If these equipment play important roles, the entire production line may be stopped. In addition, if the load is the data processing system, it can result in disruption or information losses, which can also have serious consequences. Active Voltage Conditioner (AVC) is the most appropriate solution to overcome voltage oscillations problem in low voltage grid [1-3]. The AVC system consists of a grid-side converter (Shunt converter) and a load-side converter (Series converter) connected via a DC circuit, and a transformer connected in series between the load, source. The diagram of AVC is shown in Fig. 1. In that, the load-side converter uses a 3-bridge common DC voltage diagram to compensate voltage fluctuation for each phase, the grid-side converter is a 3 -phase voltage source inverter operating in active rectifier mode that allows bidirectional energy exchange between the grid and the DC circuit to compensate voltage sag and swell.

The control system for the active voltage conditioner is divided into two parts: the active rectifier control is implemented based on the gridvoltage oriented vector principle [4], the control part of the load-side converter uses scalar control principle for each $\mathrm{H}$-bridge circuit to ensure creating 120-degree-difference phase voltages exactly according to [5-7]. These control structures have also

ISSN: $2734-9373$

https://doi.org/10.51316/jst.150.ssad.2021.31.1.15

Received: 16 June 2020; accepted: 24 November 2020 been implemented on the DSP (digital signal processor) card of Texas Instrument, which shows a good and reliable dynamic response for grid voltage fluctuations. However, these works have not indicated how to simultaneously integrate control structures using DSP for 3-phase active voltage conditioner, including control structures for the gridside converter and load-side converter. Therefore, this paper will propose the active voltage conditioner control system including regulator digitization, DSP resource, and working time frame allocation. In this system, each DSP will take on a control structure and the DSPs will link together through CAN communication standard, so the active voltage conditioner control system will be more reliable and upgradeable.

\section{Active Voltage Conditioner Control Structure}

The control structure of the grid-side converter is designed on a closed synchronous system $d q^{+}$and $d q^{-}$oriented to the grid voltage. Grid-side converter control consists of two current loops and a DCvoltage loop. DC voltage controller is used to stabilize the voltage on the capacitor and regulate the reference values for current controllers. The current loops control both the positive and negative sequence components, the value of this current component is calculated based on the grid voltage phase angle according to the phase-locked loop algorithm, combined with the decoupled double synchronous reference frame (decoupled double synchronous reference frame phase-locked loop - DDSRF PLL). PI controller parameters for the current loop circuit are designed in the frequency domain considering the model of the LCL filter circuit and the control system delay, the parameters of PI controller for the DC loop circuit are designed according to the characteristics of the quadratic oscillator [4]. 


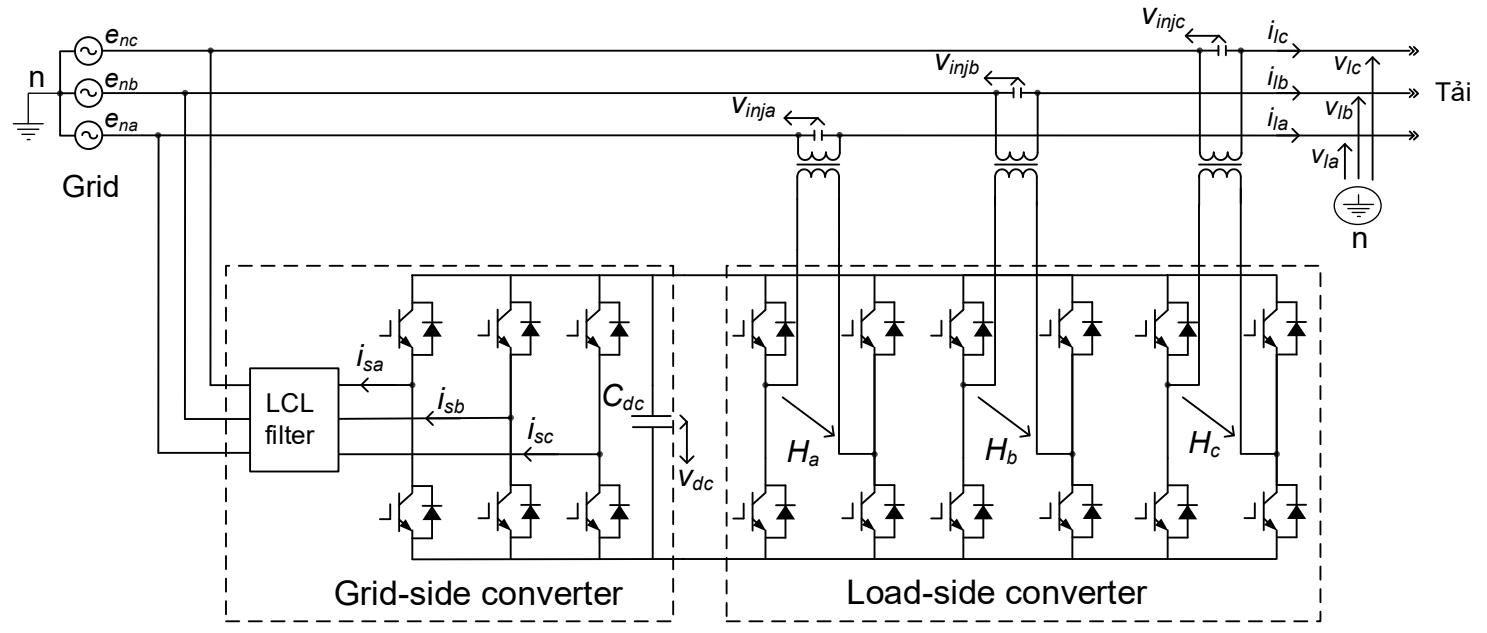

Fig. 1. Three-phase AVC diagram

The control structure for the load-side converter implements the principle of scalar control for each $\mathrm{H}$ bridge circuit in voltage mode, the PR controller is used to eliminate static deviations for the voltage loops. The PR controller parameters for the voltage loop are designed in the frequency domain based on the desired phase margin (PM) and magnitude (GM). The reference values of the voltage loops are calculated based on the difference between the desired r.m.s.voltage value (for example $220 \mathrm{Vac}$ ) and the r.m.s. voltage of the grid. In addition, the SOGI PLL algorithm (Second-order generalized integrator based phase-locked loops) is used to synchronize each of the grid voltage phases [5].

Equivalent circuits converted to the secondary side of transformer are determined according to (1):

$$
Z_{e q S}=\left(\frac{r_{p}}{N^{2}}+r_{s}\right)+j\left(\frac{x_{\sigma p}}{N^{2}}+x_{\sigma s}\right)=R+j \omega_{1} L_{\sigma},
$$

where: $N$ is the ratio of the transformer, $r_{p}$ and $r_{s}$ are the internal resistance of the primary and secondary winding, $x_{p}$ and $x_{s}$ are the primary and secondary dissipation reactance. The transfer function of the voltage needed to be compensated and the modulation coefficient for each phase is determined according to (2).

$$
G_{m v}(s)=\frac{v_{i n j a}(s)}{m_{a}(s)}=\frac{1}{N^{2}} \frac{V_{d c}}{s^{2} L_{\sigma} C+s R C+1} .
$$

The PR controller has a resonant frequency same with the grid voltage fundamental frequency $\varpi_{l}$, so the PR transfer function has the following form:

$$
G_{P R}^{c}(s)=k_{p r}+\frac{k_{r} s}{s^{2}+\left(\omega_{1}\right)^{2}}
$$

The cutoff frequency $\omega_{c}$ (selected in a range of $500 \mathrm{~Hz} \div 600 \mathrm{~Hz})$ is 10 times larger than the fundamental frequency $(50 \mathrm{~Hz})$, then the PR controller magnitude at the cutoff frequency approximately equals to $k_{p}$, and the coefficient $k_{p}$ is obtained:

$$
\begin{aligned}
& \left|G_{P R}^{c}(j \omega)\right|_{\omega=\omega_{c}}\left|G_{m v}(j \omega)\right|_{\omega=\omega_{c}}=1 \\
& \rightarrow k_{p r} \approx \frac{1}{\left|G_{i v}(j \omega)\right|_{\omega=\omega_{c}}}
\end{aligned}
$$

Coefficient $k_{r}$ is determined based on the selected phase margin $\left(30^{\circ} \div 60\right.$ to choose from $)$ and is calculated by (5).

$$
k_{r}=\frac{\tan \left(A_{c}\right) k_{p}\left(\omega_{1}^{2}-\omega_{c}^{2}\right)}{\omega_{c}}
$$

where: $A_{c}=P M_{c}-\left[\left.G_{m v}(j \omega)\right|_{\omega=\omega_{C}}+180^{\circ}\right]$

To implement in the microcontroller, the Laplace operators in the regulators need to be approximated to the $\mathrm{Z}$ domain to obtain the differential equations $[5,6]$. The PR regulator needs to consider delay when installed on the DSP (at least one sampling cycle), the $\mathrm{PR}$ regulator transfer function is rewritten in (6).

$$
G_{P R}^{c}(s)=k_{p r}+k_{r} \frac{\cos \left(\theta_{d}\right) s-\omega_{1} \sin \left(\theta_{d}\right)}{s^{2}+\left(\omega_{1}\right)^{2}}
$$

where: $\theta_{d}=\omega_{1} N T_{s}(N$ is an integer and is chosen to be 1), $T_{s}$ - sampling period of PR regulator, $h$-harmonic order).

The PR regulator is rewritten in $\mathrm{Z}$ domain as (7).

$$
G_{P R}^{d}(z) \approx k_{p r}+k_{r} T_{s} \frac{-\cos \theta_{d}+\left(\cos \theta_{d}-\omega_{1} T_{s_{-} P R} \sin \theta_{d}\right) z}{z^{2}+\left(\omega_{1}^{2} T_{s_{-} P R}^{2}-2\right) z+1}
$$

In the grid-side converter control structure, the PI controller is discretized by the Tustin method [9].

$$
G_{P I}^{d}(z) \approx k_{p_{-} P I}+k_{i_{-} P I} \frac{T_{s_{-} P I}}{2}\left(\frac{z+1}{z-1}\right)
$$

DSP digital signal processors are known as special microcontrollers with the capability of 
executing control algorithms that require high computational volume, with very high accuracy and speed.

Developed for power electronic converter control fields for a wide range of applications, the DSP TMS320F28377s is a 32-bit static comma microcontroller of the new C2000 family of Texas Instruments. This microcontroller series allows operation with quartz frequency up to $200 \mathrm{MHz}$, in addition, the 32-bit floating point arithmetic engine called CLA (Control Law Accelerator) for computational processing is integrated on the microcontroller, to execute the control algorithm in parallel with performing other tasks on CPU. From the architecture of this TMS320F28377s DSP series, 2 control structures for the grid-side and load-side converter are implemented on each DSP and the DSPs are linked via CAN communication in Fig. 2. CAN communication is highly stable due to message detection and error handling, the possibility that a message will not be detected is very low $\left(4,7.10^{-11}\right.$ baud rate). Communication using differential signal transmission has reduced the impact of electromagnetism, besides, using only 2 wires on the transmission line makes the pairing system simpler and safer.
Fig. 3 shows the program structure diagram on the DSP for the grid-side converter. DSP uses 3 PWM channels including channels PWM6, PWM7, PWM8 to control the IGBT of the power circuit. Grid-side currents $i_{s a}, i_{s b}, i_{s c}$ are measured by current sensors of LEM company, phase grid voltages $e_{n a}$, $e_{n b}, e_{n c}$ and DC voltage are passed through the measuring circuit, then sent to ADC channels A0, A1, A2 A3, B0, B1, B2 of DSP for signal reading. In addition, the DSP uses GPIO 63 and GPIO 64 to control the capacitor charge circuit during the start-up for the grid-side converter, the GPIO 72 and GPIO 73 are used for CAN communication function to connect to Master.

In DSP, 2 CPU and ClA cores are implemented parallelly. The CPU has to initialize ADC, PWM, CLA, CAN peripherals and the system's data acquisition and monitoring operations are also performed in CPU. The CLA performs ADC reading, executes control loops, phase-locked loop block and updates the modulation coefficient value for the register of PWM 6, PWM 7, PWM 8.

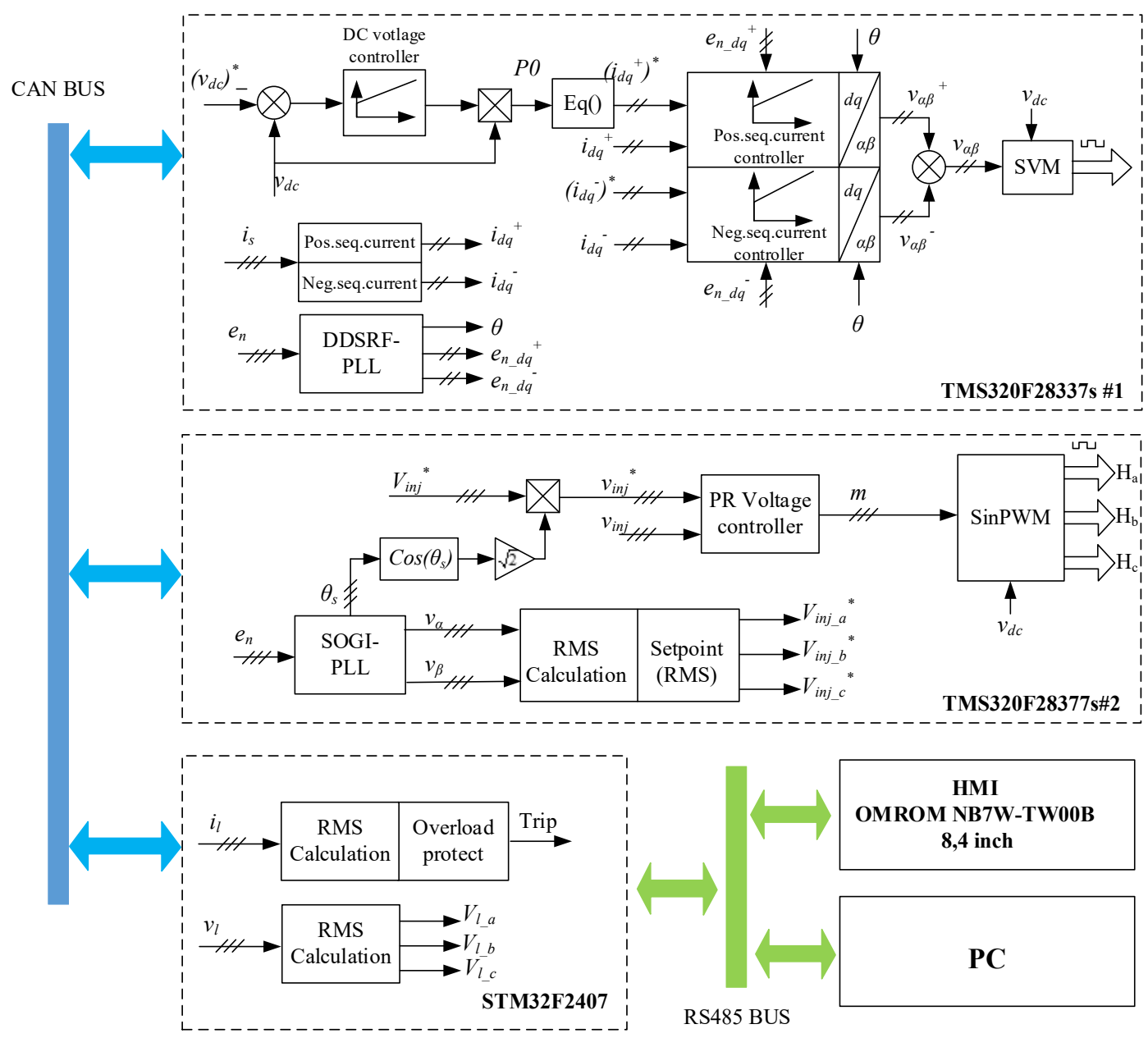

Fig. 2. Active voltage conditioner (AVC) control structure using 2 DSPs linked via CAN communication 


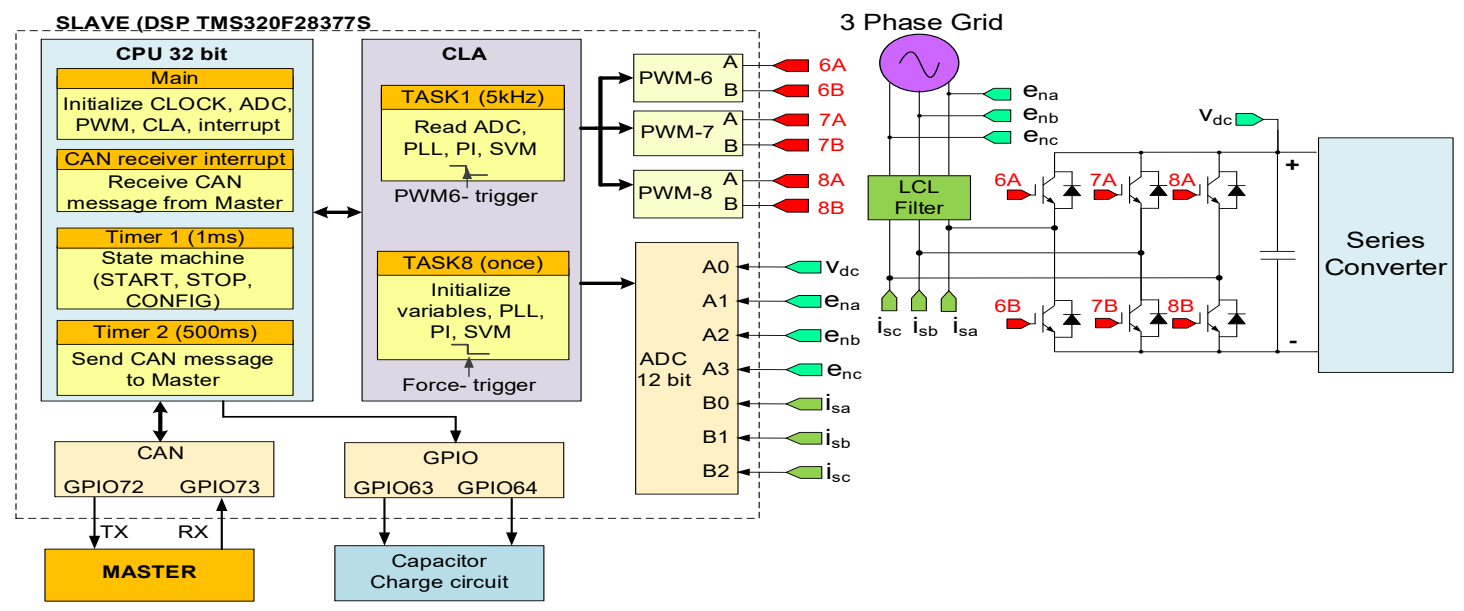

Fig. 3. Program structure on DSP for Shunt Converter.

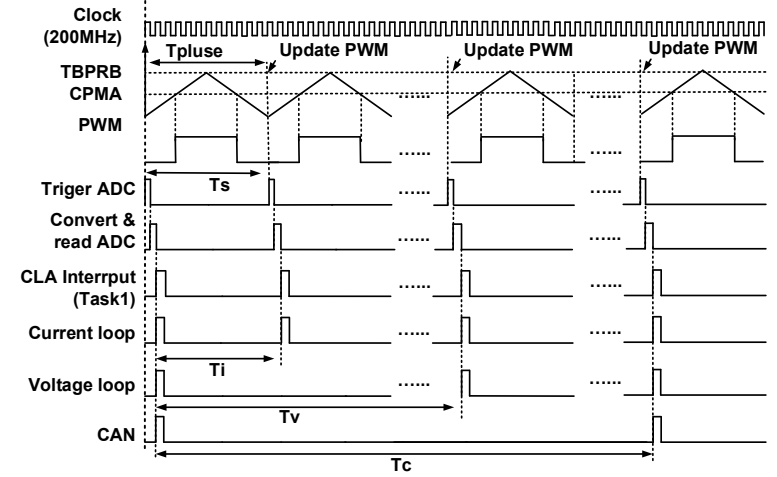

Fig. 4. Time frame on DSP for Shunt Converter

The program timeframe on the DSP for the gridside converter is depicted in Fig. 4. The PWM channel (PWM6) generates pulses at $5 \mathrm{kHz}$, which produces an ADC trigger event when PWM counter is zero. ADC channels A0, A1, A2, A3, B0, B1, B2 convert analog signals $\left(v_{d c}, e_{n a}, e_{n b}, e_{n c}, i_{s a}, i_{s b}, i_{s c}\right)$ to digital signals. At the end of the ADC conversion, an event is used to trigger the program in the CLA interrupt (task1). In CLA interrupt, current controller is executed with a sampling cycle $\left(T_{i}\right)$, which equals to the pulse generator cycle $\left(T_{p u l s e}\right)-200 \mu \mathrm{s}$, voltage controller on DC capacitor is executed with sampling cycle $\left(T_{v}\right)$ which is 10 times the current controller sampling cycle - 2 ms. After finishing the computation in CLA, the modulation coefficient is updated to registers of PWM6, PWM7, and PWM8. In the CPU, the DSP transmits the CAN messages to the BUS with a cycle $\left(T_{c}\right)$ of $500 \mathrm{~ms}$. Received CAN messages are executed in CAN received interrupt routine.

Fig. 6 shows the program structure diagram on the DSP for load-side converter. The DSP uses 6 PWM channels including PWM6 and PWM7, PWM8 and PWM9, PWM10 and PWM11 to generate pulses that control the IGBT, respectively for $H_{a}$ phase, $H_{b}$ phase, and $H_{c}$ phase. Three-phase grid voltages $e_{n a}$,

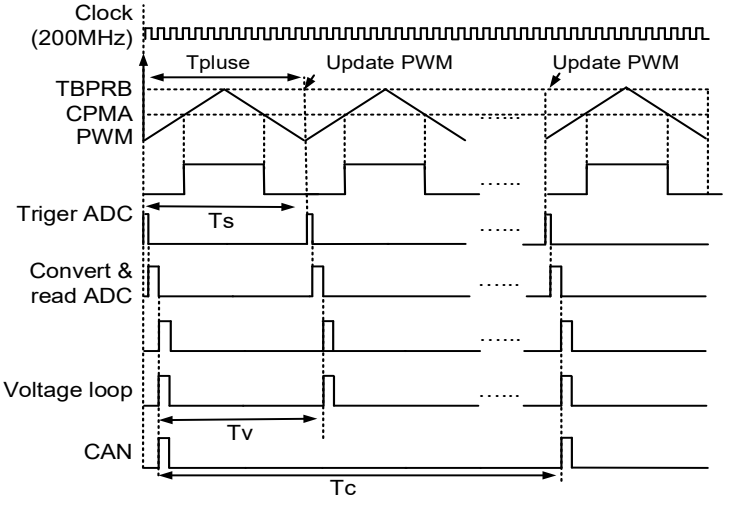

Fig. 5. Time frame on DSP for Series Converter

$e_{n b}, e_{n c}$, three compensated voltages $v_{i n j a}, v_{i n j b}, v_{i n j c}$ and DC voltage $v_{d c}$ are passed through the measuring circuit, then fed to ADC channels A0, A1, A2, A3, $\mathrm{B} 0, \mathrm{~B} 1, \mathrm{~B} 2$ of DSP for signals reading. GPIO 72 and GPIO 73 are used for CAN communication function to connect the slave to Master. Similar to grid-side converter, DSP uses 2 CPU and CLA implemented parallelly.

The program timeframe on the DSP for the loadside converter is illustrated in Fig. 5. The PWM channel (PWM6) generates pulses at $5 \mathrm{kHz}$ which produces an ADC trigger event when the PWM counter is zero. ADC Channels A0, A1, A2, A3, B0, $\mathrm{B} 1, \mathrm{~B} 2$ convert analog signals $\left(v_{d c}, e_{n a}, e_{n b}, e_{n c}, v_{i n j a}\right.$, $\left.v_{i n j b}, v_{i n j c}\right)$ to digital signals. At the end of the ADC conversion, an event is used to trigger the program in the CLA interrupt (task1). In CLA interrupt, the voltage controller is executed with sampling cycle $\left(T_{v}\right)$, which equals to pulse generator cycle $\left(T_{p u l s e}\right)$ $200 \mu$ s. After finishing the computation in CLA, the modulation coefficient is updated to registers of PWM 6, PWM7, PWM8, PWM9, PWM10 and PWM11. For communications, CAN message from Slave circuit of Series converter are also transmitted with the same cycle as Shunt converter $(T c)$ - $500 \mathrm{~ms}$. 
SLAVE (DSP TMS320F28377S

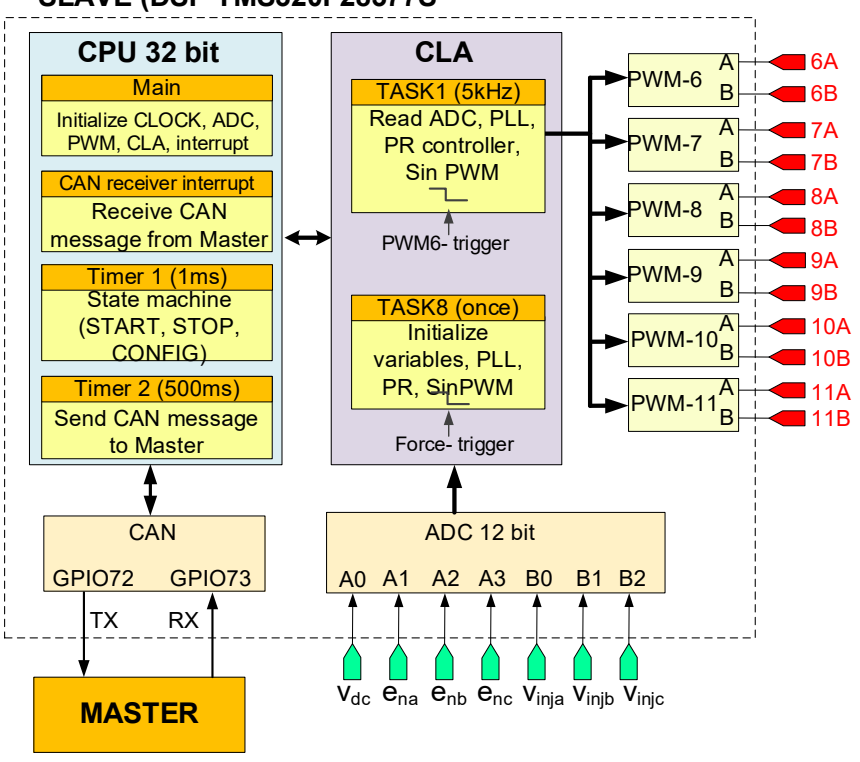

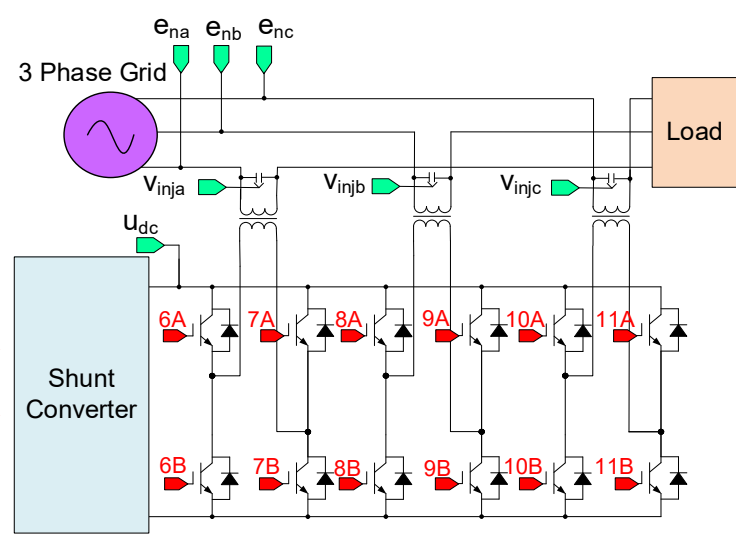

Fig. 6. Program structure on DSP for Series Converter

\section{Experimental Model and Result}

Parameters in the active voltage conditioner with a power of $5 \mathrm{kVA}$ are shown in Table 1.

Table 1. Experimental parameters [8]

\begin{tabular}{l|l}
\hline \hline \multicolumn{2}{c}{ Grid-side and load-side converter } \\
\hline \hline IGBT & $\begin{array}{l}\text { IGBT } \\
\text { SKM75GB176D }\end{array}$ \\
\hline Driver & IC HCPL316J \\
\hline Current measurement & $\begin{array}{l}\text { Current transducer } \\
\text { LEM LA55-P/SP1 }\end{array}$ \\
\hline $\begin{array}{l}\text { Isolated IC for voltage } \\
\text { measurement }\end{array}$ & IC HCPL7800A \\
\hline Control card & $\begin{array}{l}\text { DSP TMS320F28377s } \\
\text { launchpad }\end{array}$ \\
\hline Transformer parameters & $\begin{array}{l}\text { Power: 4.5kVA } \\
\text { Turns ratio: 2:1 }\end{array}$ \\
\hline \hline & $\begin{array}{l}\text { IC ACS712 5A } \\
\text { Current Transformer } \\
50 \mathrm{~A} / 5 \mathrm{~A}\end{array}$ \\
\hline \hline $\begin{array}{l}\text { Load current } \\
\text { measurement }\end{array}$ & IC HCPL7800A \\
\hline $\begin{array}{l}\text { Isolated IC for voltage } \\
\text { measurement }\end{array}$ & $\begin{array}{l}\text { Kit STM32F407 } \\
\text { Discovery }\end{array}$ \\
\hline $\begin{array}{l}\text { Control and data } \\
\text { acquisition card }\end{array}$
\end{tabular}

Voltage sag can be created by generating a three-phase or two-phase or 1-phase short circuit via resistors, the short-circuit resistance and reactance are calculated. The system voltage will be dropped due to the power limitation of the $5 \mathrm{kVA}$ isolated transformer located at source-side. The voltage drop value varies based on the resistance adjustment of each phase, in the range of $0-10 \Omega$.

AVC control system is designed according to MASTER - SLAVE structure, connected by CAN communication. In this structure SLAVE is the TMS320F28377S DSP signal microprocessors which execute control structures for each grid-side and loadside converter as shown in Fig. 2. MASTER is a digital microprocessor, The STM32F407 Discovery Kit signal collects data to display and command control signals for the SLAVE.

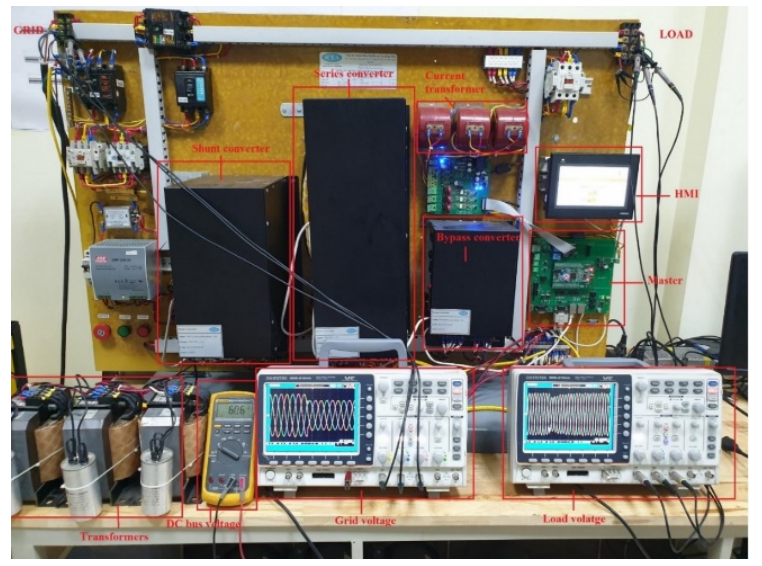

a) Experimental model AVC 5kVA.

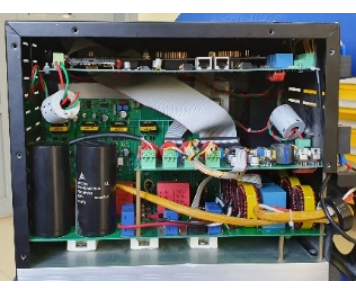

b) Grid-side converter

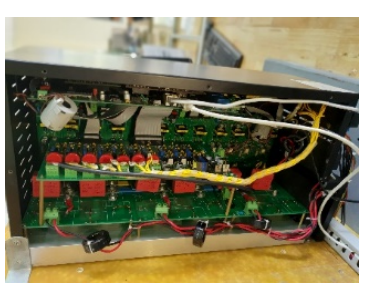

c) Load-side converter
Fig. 7. Active voltage conditioner $5 \mathrm{kVA}$. 
Monitoring and data collection level MASTER solves control problems, such as setting parameters for regulators, setting operating modes to allow AVC to compensate voltage sag and swell when the grid voltage is not within the range from $90 \% \div 110 \%$ of the nominal value, measure the load current to determine the overload protection for the system, collect and display data on HMI.

The AVC is tested with 3 cases of voltage sag. In all cases, the DC voltage remains the same at $600 \mathrm{Vdc}$

Case 1: 3-phase voltage sag, each phase voltage has r.m.s.value before being sagged is $226.2 \mathrm{~V}$; $225.3 \mathrm{~V} ; 225.7 \mathrm{~V}$, respectively. The system creates all 3 -phases sag simultaneously in 10 seconds with corresponding values for each phase $134.9 \mathrm{~V}$; $135.1 \mathrm{~V} ; 135.2 \mathrm{~V}$. When the AVC system operates, the load voltage is restored to $224.4 \mathrm{~V} ; 224.7 \mathrm{~V}$;

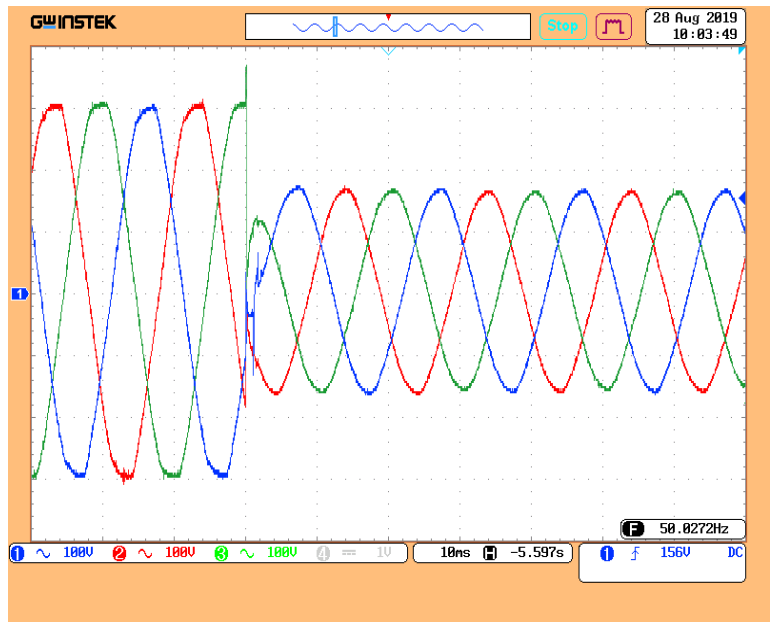

a) Grid voltage $(100 \mathrm{~V} / \mathrm{div}, 10 \mathrm{~ms} / \mathrm{div})$

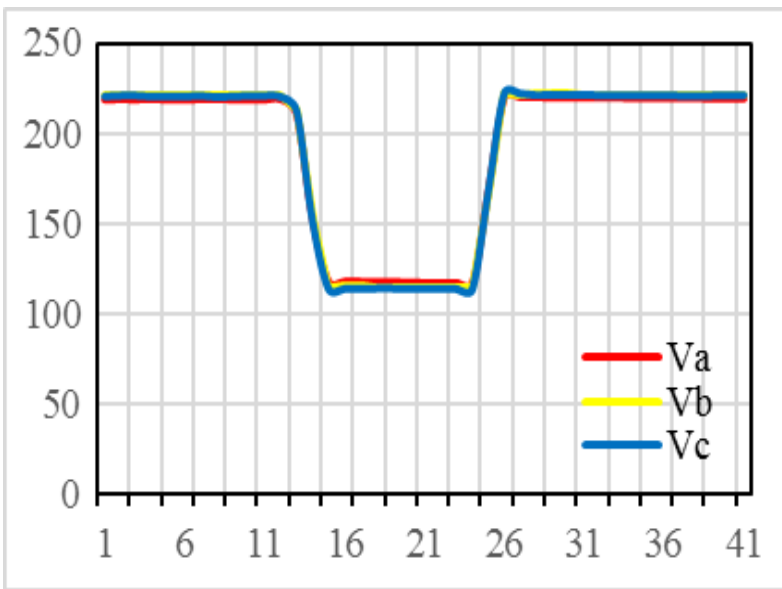

c) R.m.s. value of grid voltage measured by CW140.
$225.7 \mathrm{~V}$. The maximum recovery voltage deviation is $0.8 \%$, the voltage recovery time is $40(\mathrm{~ms})$.

Case 2: 1-phase voltage sag, the voltage of each phase has r.m.s.value before being sagged is $225.3 \mathrm{~V}$; $224.4 \mathrm{~V} ; 224.8 \mathrm{~V}$, respectively. The system creates a voltage sag of phase $A$, reduces the voltage to $101.6 \mathrm{~V}$ in 10 seconds, voltage of phase $\mathrm{B}$ and phase $\mathrm{C}$ remain unchanged. When the AVC system operates, the A-phase load voltage is restored to $225.7 \mathrm{~V}$. The maximum recovery voltage deviation is $0.18 \%$, the voltage recovery time is $40(\mathrm{~ms})$.

Case 3: 3-phase voltage swell, the voltage of each phase has r.m.s. value before being increased is $225.3 \mathrm{~V} ; 224.8 \mathrm{~V} ; 224.4 \mathrm{~V}$, respectively. Autotransformer increases voltage values to $258.1 \mathrm{~V}$; $257.7 \mathrm{~V} ; 258 \mathrm{~V}$ in 10 seconds. When the AVC system operates, the load voltage is restored to $225.3 \mathrm{~V}$; $225.3 \mathrm{~V} ; 224.9 \mathrm{~V}$.

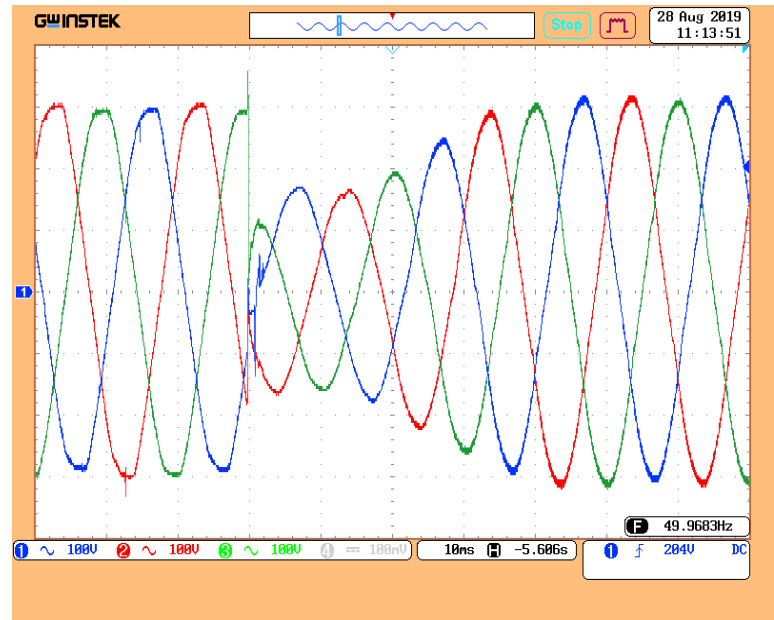

b) Load voltage $(100 \mathrm{~V} / \mathrm{div}, 10 \mathrm{~ms} / \mathrm{div})$

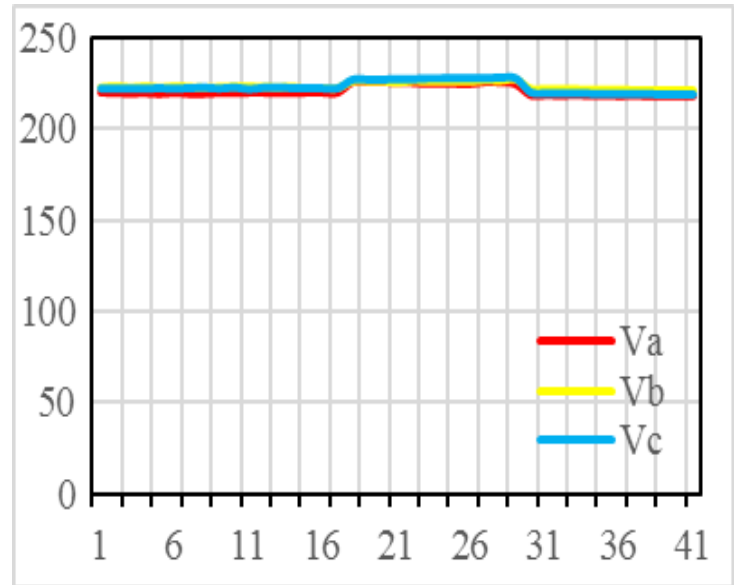

d) R.m.s. value of load voltage measured by CW140.

Fig. 8. Grid voltage and load voltage in case of 3-phase voltage sag. 


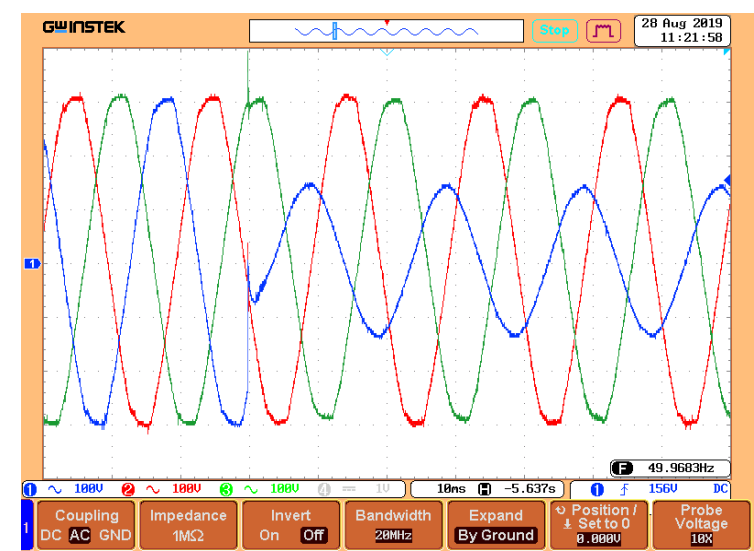

a) Grid voltage (100V/div, $10 \mathrm{~ms} / \mathrm{div})$

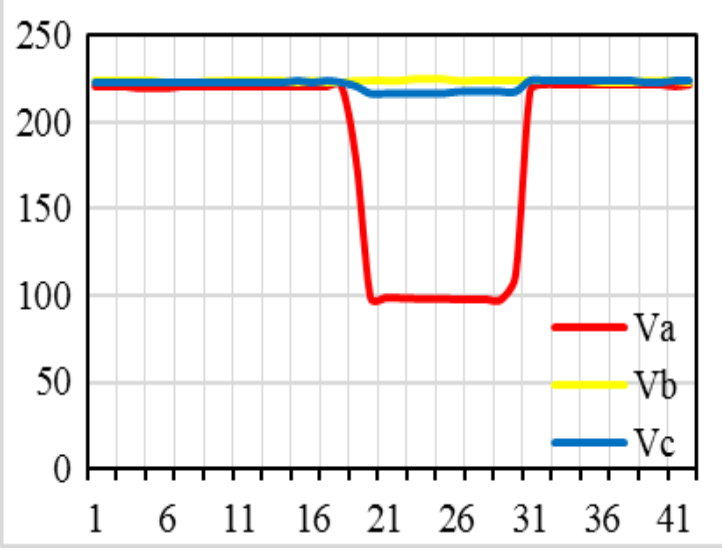

c) R.m.s. value of grid voltage measured by CW140.

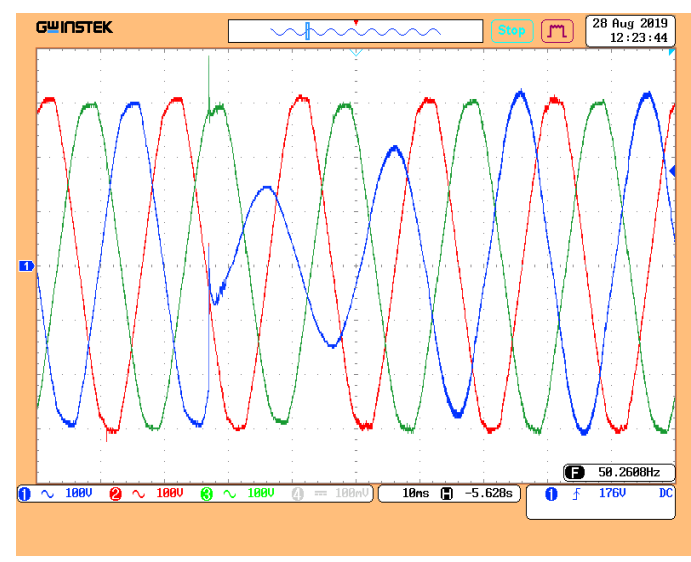

b) Load voltage (100V/div, $10 \mathrm{~ms} / \mathrm{div})$

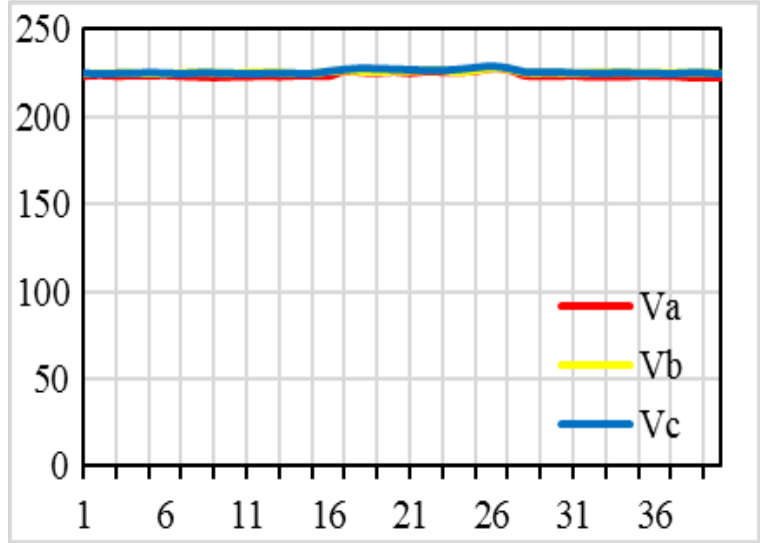

d) R.m.s. value of load voltage measured by CW140.

Fig. 9. Grid voltage and load voltage in case of 1-phase voltage sag.

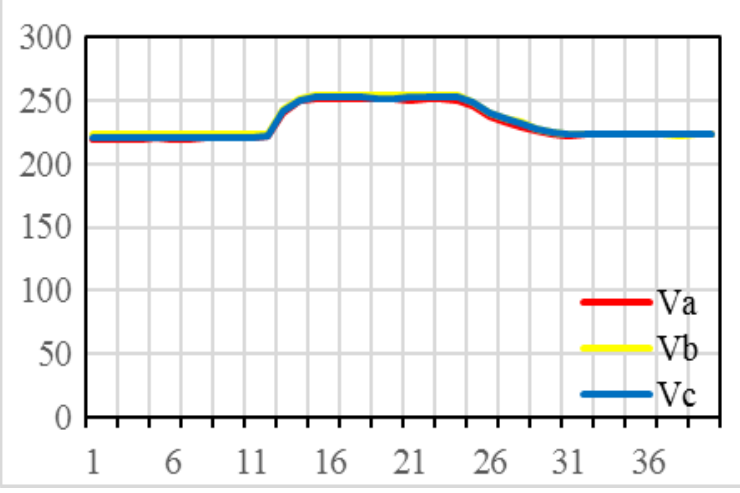

a) Grid voltage

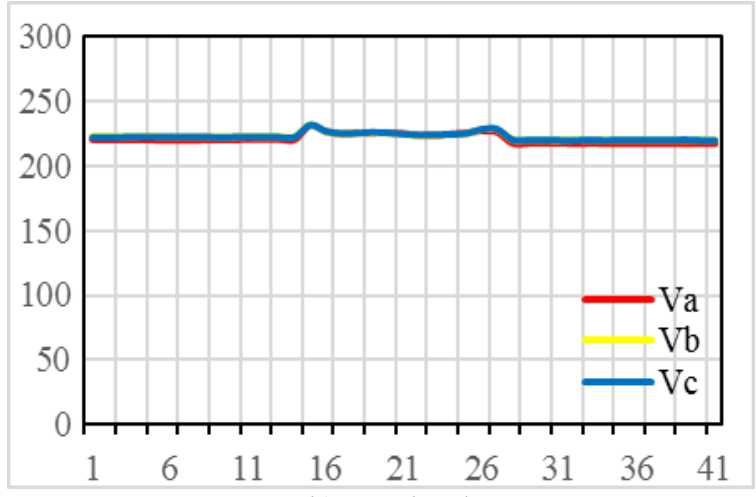

b) Load voltage

Fig. 10. R.m.s. value of voltage measured by CW140 in case of 3-phase voltage swell.

\section{Conclusion}

The paper has presented a three-phase active voltage conditioner structure that is capable of stabilizing the load voltage when the grid voltage fluctuates. The control and communication system of the active voltage conditioner is fully implemented by digital signal processing DSP. The results show that the load voltage can be steadily adjusted to follow the rated value within two grid voltage cycles, the deviation of voltage less than $1 \%$.

\section{Acknowledgements}

This research is funded by the Ministry of Science and Technology (Vietnam) under project number KC.05.03/16-20.

\section{References}

[1] J.G.Nielsen and F.Blaabjerg, A detailed comparison of system topologies for dynamic voltage restorers, in IEEE Transactions on Industry Applications, vol. 41, no. 5, pp. 1272-1280, Sept.-Oct. 2005. https://doi.org/10.1109/TPEL.2017.2772845 
[2] H.Hafezi and R.Faranda, Dynamic Voltage Conditioner: A New Concept for Smart Low-Voltage Distribution Systems, in IEEE Transactions on Power Electronics, vol.33, no.9, pp.7582-7590, Sept. 2018. https://doi.org/10.1109/TPEL.2017.2772845

[3] Amit Meena, Shirazul Islam, Sandeep Anand, Yogesh Sonawane, Sanjay Tungare, Design and control of single-phase dynamic voltage restorer, Springer India, August 2017, Vol 42, Issue 8, pp 1363-1375. https://doi.org/10.1007/s12046-017-0653-5

[4] Vu Hoang Phuong, Hoang Thanh Nam, Tran Trong Minh, Nguyen Huy Phuong. , A control strategy for active rectifier using LCL filter in unbalance voltage grid. Special issue on measurement, control and automation, Vol. 20, 12/2017 (Vietnamese).

[5] Vu Hoang Phuong, Nguyen Dinh Ngoc, Tran Trong Minh, Nguyen Quang Dich, PR controllers for series converter in active voltage conditioner. Special issue on measurement, control and automation, Vol. 21, 04/2018 (Vietnamese).

[6] Phuong Vu, Ngoc Dinh, Nam Hoang, Quan Nguyen, Dich Nguyen, Minh Tran, A generalized parameters tuning of PR Controllers for dynamic voltage restorer, pp.1709-1717, Vol 9, No 4, International Journal of Power Electronics and Drive System (IJPEDS), Sep 11, 2018.

https://doi.org/10.11591/ijpeds.v9.i4.pp1709-1717

[7] Vu Hoang Phuong, Tran Trong Minh, Vu Ngoc Van, Nguyen Huy Phuong, Nguyen Quang Dich, A Linear control for Active voltage conditioner, The 3rd ASEAN Smart Grid Congress \& The 5th International Conference on Sustainable Energy. https://doi.org/10.1109/TIA.2005.855045

[8] Vu Thi Ngoc Van, Nguyen Dinh Ngoc, Hoang Thanh Nam, Tran Trong Minh, Pham Quang Dang, Nguyen Huy Phuong. Test-bench setup for Active Voltage Conditioner in low voltage. The 5th Vietnam International Conference and Exhibition on Control and Automation-VCCA 2019 (Vietnamese).

[9] Simone Buso; Paolo Mattavelli, Digital Control in Power Electronics, 2nd Edition, in Digital Control in Power Electronics, 2nd Edition, Morgan \& Claypool, 2015.

https://doi.org/10.2200/S00637ED1V01Y201503PEL 007 